\title{
Quality of life among siblings of patients with chronic conditions
}

\author{
Jenny Velasco, M.D. ${ }^{a}$, Verónica Ferraris, M.D. ${ }^{a}$, Alfredo Eymann, M.D. ${ }^{b}$, \\ Paula A. Coccia, M.D. ${ }^{a}$, Lidia R. Ghezzi, M.D. ${ }^{a}$, María C. Sánchez, M.D. ${ }^{c}$, \\ Carmen L. De Cunto, M.D. ', Daniel D'Agostino, M.D. ${ }^{c}$ and Jorge R. Ferraris, M.D. ${ }^{a}$
}

\begin{abstract}
Introduction. Health-related quality of life (HRQoL) is a measure of health outcomes. It assesses the subjective and overall impact of diseases on daily life. It also provides multidimensional data about physical wellbeing, family and peers relations. HRQoL studies on siblings are limited.

Objective. To compare HRQoL among siblings of pediatric patients with chronic rheumatic diseases, kidney or liver transplant and healthy children whose siblings had no chronic conditions.
\end{abstract}

Results. The siblings of children with kidney transplant (n: 65), liver transplant (n: 35), and chronic rheumatic diseases (n: 36$)$ were compared to the healthy children group (n: 51). The total siblings group had a lower, statistically significant score in the physical well-being, social support and peers, and financial resources dimensions. The siblings of kidney transplant patients had a low score in the physical wellbeing $(p<0.02$; effect size [ES]: 0.66$)$ and financial resources $(p<0.01$; ES: 0.66$)$ dimensions. The siblings of liver transplant patients perceived a lower physical well-being $(p=0.04)$, less social support and peers $(p<0.01)$, and difficulties in relation to school environment $(p<0.02)$ and financial resources $(p<0.01)$. The siblings of those with chronic rheumatic diseases had a lower score in the physical well-being $(p<0.05$; ES: 0.44$)$ and social support and peers $(p<0.01$; ES: 0.58) dimensions.

Conclusion. HRQoL among healthy children whose siblings have a chronic disease was lower in the physical well-being, social support and peers, and financial resources dimensions compared to the healthy children group.

Key words: quality of life, health-related quality of life, family, sibling relations, chronic disease.

http: / / dx.doi.org/10.5546/ aap.2020.eng.252

To cite: VelascoJ, Ferraris V, Eymann A, Coccia PA, etal. Quality of life among siblings of patients with chronic conditions. Arch Argent Pediatr 2020;118(4):252-257.

\section{INTRODUCTION}

Health-related quality of life (HRQoL) is an important tool to assess the effectiveness of medical treatment, the usefulness of health care services, and population health monitoring. ${ }^{1}$ The HRQL construct attempts to measure how the health status and/or the treatments received, affect on the subject quality of life. Measuring HRQoL implies collecting reliable, subjective information, which is stable in the short-term and can be compared to that of other subjects. ${ }^{2}$ The events occurring in the setting of a chronic condition may alter physical, psychological, and social development, not only in relation to patients but also to their family, conditioned by the ongoing need for medical supervision, prolonged medication use, and family stress, among other factors. ${ }^{3,4}$

In Argentina, more and more children develop chronic diseases. ${ }^{2}$ In developed countries; approximately $10-20 \%$ of the pediatric population, is estimated, to have a chronic condition. ${ }^{5}$

Several studies comparing HRQoL among pediatric patients with chronic conditions and healthy peers showed that those with a chronic disease had a lower HRQoL score in the physical and socio-psychological dimensions. Looking for better medical, therapeutic, and psychological tools to improve their HRQoL was also a major challenge for health care teams that worked with these patients. ${ }^{6,7}$

Families play a critical role in the management of children with chronic conditions due to the time they devote to their routine controls and hospitalizations, as well as the 
administration of medication several times a day. All these factors force all family members to change and adapt their daily life routines and learn how to live with disease, thus causing a breakdown in their lifestyle and physical, social, and education activities. ${ }^{8,9}$

Sibling relations are strong, intricate, and infinitely varied. However, most studies have reported that the siblings of children with chronic conditions are more prone to develop adaptation or behavior problems than their peers. ${ }^{10}$

It has been considered that the perception of siblings of children and adolescents with chronic conditions should be taken into account by pediatricians so that they can provide an adequate health care to all family members. In spite of their relevance, HRQoL studies on siblings are limited.

\section{OBJECTIVE}

To compare HRQoL among siblings of pediatric patients with chronic rheumatic diseases (CRDs), kidney transplant (KT) or liver transplant (LT) and healthy children whose siblings had no chronic conditions.

\section{POPULATION AND METHODS \\ Study design}

This was a hospital-based, cross-sectional, case-control study conducted at Hospital Italiano de Buenos Aires.

\section{Ethical aspects}

The study was approved by the Ethics Committee for Research Protocols of our institution. During the office visit, patients were invited to participate in the study; their parents' informed consent and the child's assent were obtained; and the KIDSCREEN-52 questionnaire was delivered.

\section{Study sample and participants}

All male and female children aged 8 to 18 years, whose siblings had a chronic disease or were healthy, with no history of hospitalizations or acute events in the 2 months before the questionnaire were included. All boys and girls who met the inclusion criteria were included.

The population was divided into 2 groups for analysis:

Group 1: Siblings of children with a chronic condition

This group included the siblings of children who had a history of KT or LT (transplanted at least 6 months before the survey administration) and of children with CRDs with at least 3 months of disease course since diagnosis. Participants were included if, at the time of the survey, they had attended the specialist office visit at Hospital Italiano together with their chronically-ill sibling. The primary care physician was responsible for inviting participants, obtaining the consent, and including the child in the study. The siblings of patients with solid organ retransplantation (kidney or liver) were excluded.

\section{Group 2: Healthy children, control group}

They were selected among children who attended Hospital Italiano for a scheduled health checkup.

\section{KIDSCREEN-52}

The KIDSCREEN-52 questionnaire was used. It is a generic, self-administered tool that has been validated in Argentina and that is used to measure 10 HRQoL dimensions ${ }^{11}$ (Annex). The KIDSCREEN-52 was simultaneously developed in 13 European countries, and has demonstrated a high level of validity and reliability (Cronbach's alpha coefficient: 0.81). ${ }^{11}$ The Argentine version includes questions about the parents' education and socioeconomic level. The questionnaire uses a Likert answer scale to establish a score for each dimension, which is then standardized to a mean of 50 points and a standard deviation (SD) of 10 points. A higher score indicated a better HRQoL. Questions referred to the events occurred in the past week. ${ }^{11}$

\section{Outcome measures}

Independent outcome measures were selected based on prior studies that had demonstrated a relation with short- and long-term results on HRQoL. ${ }^{12}$ They included parents' marital status and socioeconomic level, established using a family material resources scale (Family Affluence Scale, FAS), which showed an acceptable correlation with the parental employment modality category. The FAS is estimated using 4 questions on the number of motor vehicles and computers owned by the family, if the participant has their own room, and having had family vacations over the past 12 months. The scale is categorized into low socioeconomic level (score: 0-3), middle socioeconomic level (score: 4-5), and high socioeconomic level (score: 6-7). The association among independent outcome measures and HRQoL was estimated based on the effect size (ES). ${ }^{13}$ 


\section{Parental level of education}

Maternal and paternal education level referred to the highest completed education level. It was categorized as per the International Standard Classification of Education (ISCED). ${ }^{14}$ Other independent outcome measures were also included: type of family organization, birth order of the chronically-ill sibling and of the surveyed sibling.

\section{Statistical analysis}

Data were entered into a specially designed database using Excel and were analyzed with the STATA 13.0 software. The study and control group baseline characteristics were described by estimating the absolute frequency and percentage for categorical outcome measures. Continuous outcome measures were expressed as mean and SD. The differences among categorical outcome measures were established using the $\chi^{2}$ test, while those among continuous outcome measures, with the $t$ test.

A two-tailed t test was used to compare each group of siblings of patients with chronic conditions and the control group. A value of $p<0.05$ was considered statistically significant.

Mean scores were estimated for the $10 \mathrm{HRQoL}$ dimensions, which were standardized to a mean of $50( \pm 10)$ SD..$^{12,13}$ The standardized mean scores for both groups were compared for each dimension based on the estimated ES. To calculate the size of the standardized mean differences among groups, a value between 0.20 and 0.50 was considered a small effect; between 0.51 and 0.80 , a moderate effect and $>0.80$, a large effect. ${ }^{12}$

\section{RESULTS}

The final sample was made up of 136 siblings of patients with chronic conditions: 65 siblings of KT patients, 35 siblings of LT patients, 36 siblings of patients with CRDs, and 51 healthy children. No patients were eliminated from the study. The characteristics of both studied groups are summarized in Table 1. No significant differences were observed in the participants' sociodemographic characteristics, except for the independent outcome measure of paternal/ maternal tertiary level of education, for which a higher level of education was attained among the parents of controls compared to the group of siblings of patients with chronic conditions $(p<0.01)$ (Table 1).

Table 2 shows the HRQoL for the 3 groups of siblings of patients with chronic conditions and the group of siblings of children with no disease (control group). The differences between both studied groups in the assessment of quality of life results in terms of physical well-being, social support, and financial resources are shown in Figure 1. In each group, siblings had lower scores in the physical well-being dimension $(p<0.03$; ES: 0.36$)$. The siblings perceived a worse HRQoL in the social support and peers $(p<0.01$; ES: 0.44$)$ and financial resources ( $p<0.01 ; E S: 0.50)$ dimensions (Table 2).

In relation to HRQoL among the siblings of KT patients compared to the control group, a lower physical well-being and a worse perception of financial resources were observed in the former; however, a better score was observed in the psychological well-being, self-perception, autonomy, and school environment dimensions. The size of such differences was small $(\mathrm{ES}<0.50)$, except for the financial resources dimension, which showed a moderate size $(\mathrm{ES}=0.66)$.

The comparison of the mean HRQoL score among the siblings of LT patients and the control group (healthy children group) showed statistically significant differences in $4 / 10$ dimensions. The siblings perceived a lower physical well-being $(p=0.04)$, a worse social support $(p<0.01)$, a worse school environment $(p<0.02)$, and lower financial resources $(p<0.01)$ than healthy controls. The size of such differences was moderate $(E S>0.50)$ in all dimensions, except for the physical well-being dimension, which showed a small size $(E S=0.46)$. The psychological well-being and social acceptance dimensions also showed small differences, which were not statistically significant $(p>0.05)$.

The analysis of the HRQoL score among the siblings of patients with CRDs compared to the control group showed statistically significant differences in 2 dimensions. The siblings perceived a lower physical well-being $(p<0.05)$ and a worse social support $(p<0.01)$ compared to healthy controls. The size of such differences was small for the physical well-being dimension $(E S=0.44)$ and moderate for the social support dimension $(E S=0.58)$. The psychological wellbeing, moods and emotions, school environment, social acceptance, and financial resources dimensions also showed small differences, which were not statistically significant $(p>0.05)$.

\section{DISCUSSION}

HRQoL has not been systematically measured among the siblings of patients with chronic 
diseases. Our study shows that the perception of the quality of life is lower among healthy children who have a sibling with a chronic condition compared to the control group. This is a paradox because they are healthy children, and it depicts the impact of a child's chronic disease on all family members.
Each of the siblings of patients with chronic conditions has a lower subjective perception of physical well-being, a dimension that explores physical activity, energy, and fitness. It is believed that this outcome may evidence that both families and health care teams undervalue the status of children with chronically-ill siblings, who

TABLE 1. Characteristics of the population under study

\begin{tabular}{|c|c|c|c|}
\hline Characteristics of the population & $\begin{array}{c}\text { Siblings group } \\
\mathrm{n}: 136 \\
\end{array}$ & $\begin{array}{c}\text { Control group } \\
\mathrm{n}: 51 \\
\end{array}$ & $p$ value \\
\hline Girls, n (\%) & $62(45)$ & 29 & ${ }^{*} 0.08$ \\
\hline Age (years), mean (SD) & $12.51 \pm 2.95$ & $13.22 \pm 2.47$ & ${ }^{* *} 0.08$ \\
\hline Attending school, n (\%) & $128(94)$ & $50(98)$ & ${ }^{*} 0.44$ \\
\hline Public education, n (\%) & $60(44)$ & $15(29)$ & ${ }^{*} 0.08$ \\
\hline $\begin{array}{l}\text { Family type, } \mathrm{n}(\%) \\
\text { Traditional family } \\
\text { Single-parent family }\end{array}$ & $\begin{array}{l}84(61) \\
30(22)\end{array}$ & $\begin{array}{l}38(74) \\
13(25)\end{array}$ & ${ }^{*} 0.4$ \\
\hline $\begin{array}{l}\text { Socioeconomic level } \\
\text { Low } \\
\text { Middle-high }\end{array}$ & $\begin{array}{l}43(32) \\
93(68)\end{array}$ & $\begin{array}{c}8(15) \\
21(41)\end{array}$ & ${ }^{*} 0.8$ \\
\hline $\begin{array}{l}\text { Birth order of chronically-ill sibling } \\
\text { First child } \\
\text { Second child or younger }\end{array}$ & $\begin{array}{c}27(20) \\
109(80)\end{array}$ & $\begin{array}{c}8(15) \\
43(84)\end{array}$ & ${ }^{*} 0.6$ \\
\hline $\begin{array}{l}\text { Birth order of surveyed sibling } \\
\text { First and second child } \\
\text { Third child or younger }\end{array}$ & $\begin{array}{l}111(81) \\
35(25)\end{array}$ & $\begin{array}{l}35(68) \\
26(50)\end{array}$ & ${ }^{*} 0.08$ \\
\hline Maternal tertiary/university education & $54(40)$ & $51(100)$ & ${ }^{*} 0.01$ \\
\hline Paternal tertiary / university education & $41(30)$ & $51(100)$ & ${ }^{*}<0.01$ \\
\hline
\end{tabular}

${ }^{*} \chi^{2} ;{ }^{* *}$ Student's $t$ test.

SD: standard deviation.

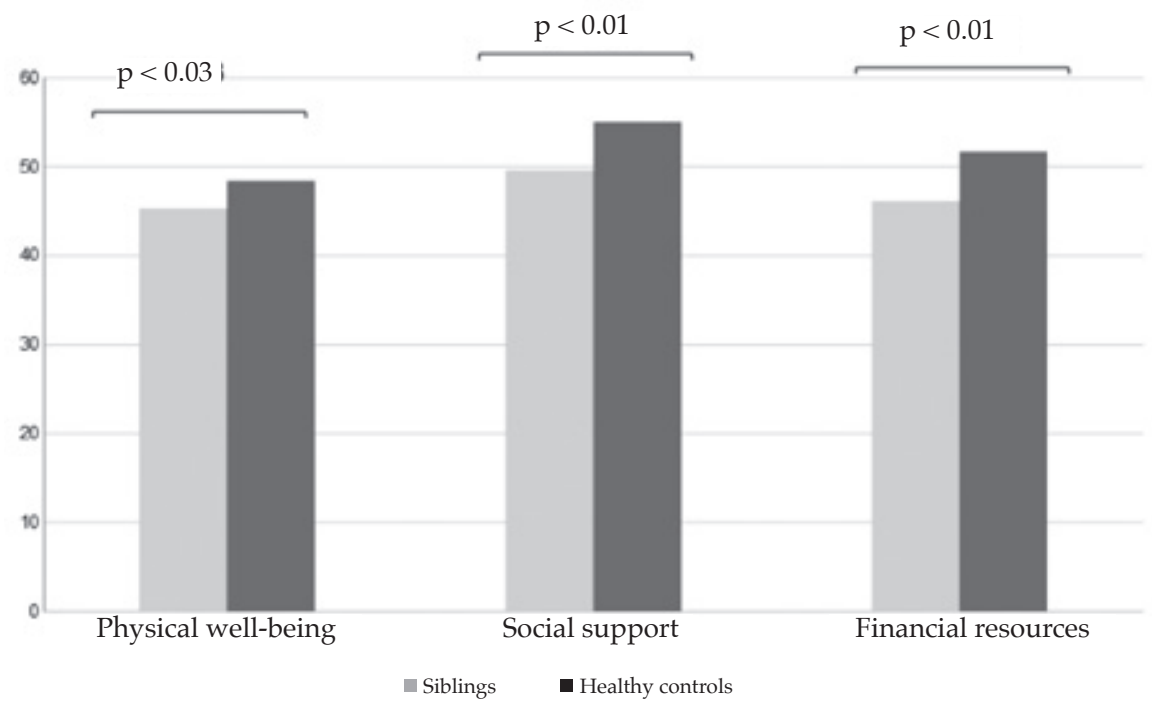


showed a negative impact in this dimension. It is known that the adequate functioning of family and interpersonal relations is one of the major contributing factors to psychosocial adaptation, both for chronically-ill and healthy children, so that they are able to have a better quality of life, because their self-image is important for their psychological well-being.

Other domains with a negative impact among the siblings of patients with chronic conditions were the peers and social support and the financial resources dimensions. Our null hypothesis was accepted. The siblings of patients with chronic conditions had a lower HRQoL than the control group, although they were healthy.

The psychosocial impact of having a sibling with a chronic physical disease has been analyzed in several studies. ${ }^{6,7-12}$ However, in our study, no statistically significant differences have been observed in the studied groups.

The siblings of KT and LT patients had a lower HRQoL score in the financial resources dimension compared to the control group. This study showed statistically significant results in the financial resources dimension. It is the first study in the bibliography to describe such outcomes. This dimension explores whether siblings feel they have enough financial resources available to have a lifestyle similar to that of the control group, and this gives them the chance to do activities together with their peers.

A family with a chronically-ill child has trouble dealing with having to miss work due to frequent medical checkups and hospitalizations, thus putting them at risk for losing their job; they also have additional expenses on medication, transportation expenses to attend medical controls, and health insurance payments, which lead to a reduced family income. Healthy siblings feel that there is less money available for their own expenses or family members feel that they cannot allow to buy things for themselves, thus impacting their lifestyle.

This study has certain limitations, such as the lack of a 1:1 ratio between the groups. HRQoL studies on siblings are limited. It is important to continue with research and point out the factors and impact on siblings of patients with chronic conditions that would help to improve their HRQoL.

\section{CONCLUSIONS}

The siblings of patients with KT, LT, and CRDs had a worse HRQoL in relation to physical well-being and peers and social support, and considered that they did not have enough money available for their recreational, daily and personal activities.

\section{Acknowledgments}

We would like to thank the Medical Board of the Ronald McDonald House and Verónica Mamondi, Master and B.S. in Nutrition, and the Ethics Committee for Research Protocols (Comite de Ética y Protocolos de Investigación, CEPI) of Hospital Italiano de Buenos Aires, who helped with the statistical analysis. Particularly, we thank the team of professionals and assistants who worked at the Ronald McDonald House and who trusted our research and opened its doors. We would also like to thank the children and their families who enthusiastically, patiently and selflessly participated in this study.

TABLE 2. Health-related quality of life among siblings of children with chronic conditions and healthy children

\begin{tabular}{|c|c|c|c|c|}
\hline \multirow[t]{2}{*}{ Dimensions } & \multirow{2}{*}{$\begin{array}{c}\text { Siblings group } \\
(n: 136) \\
\text { Mean } \pm \text { SD }\end{array}$} & \multirow{2}{*}{$\begin{array}{c}\text { Grupo control } \\
(\mathrm{n}: 51) \\
\text { Mean } \pm \text { SD }\end{array}$} & \multirow[t]{2}{*}{${ }^{*} p$ value } & \multirow[t]{2}{*}{ ES } \\
\hline & & & & \\
\hline Physical well-being & $45.3 \pm 8.7$ & $48.4 \pm 8.3$ & 0.03 & 0.36 \\
\hline Psychological well-being & $49.2 \pm 11.2$ & $49.9 \pm 8.4$ & 0.07 & 0.07 \\
\hline Moods and emotions & $48.6 \pm 12.4$ & $49.2 \pm 10$ & 0.74 & 0.05 \\
\hline Self-perception & $51.0 \pm 9.3$ & $49.9 \pm 9.5$ & 0.47 & 0.12 \\
\hline Autonomy & $49.1 \pm 10.8$ & $48.8 \pm 10.6$ & 0.84 & 0.03 \\
\hline Parent relations and home life & $49.8 \pm 10.6$ & $50.4 \pm 8.9$ & 0.76 & 0.05 \\
\hline Social support and peers & $49.6 \pm 13$ & $55.0 \pm 10.4$ & 0.01 & 0.44 \\
\hline School environment & $51.0 \pm 11.5$ & $51.8 \pm 10.1$ & 0.69 & 0.07 \\
\hline Social acceptance & $50.63 \pm 10.7$ & $52.0 \pm 9.2$ & 0.41 & 0.13 \\
\hline Financial resources & $46.1 \pm 12$ & $51.7 \pm 8$ & 0.01 & 0.50 \\
\hline
\end{tabular}

SD: standard deviation; ES: effect size.

* Student's $t$ test. 


\section{REFERENCES}

1. Rivera C, Mamondi V, Lavin Fueyo J, Jouglard E, et al. Calidad de vida relacionada con la salud en niños con y sin trastornos crónicos. Estudio multicéntrico. Arch Argent Pediatr. 2015; 113(5):404-10.

2. Berra S, Bustingorry V, Henze C, Díaz M, et al. Adaptación transcultural del KIDSCREEN, para medir la calidad de vida relacionada con la salud en población en Argentina de 8 a 18 años. Arch Argent Pediatr. 2009; 107(4):307-14.

3. Mastroyannopoulou K, Sclare I, Baker A, Mowat AP. Psychological effects of liver disease and transplantation. Eur J Pediatr. 1998; 157(10):856-60.

4. Taylor R, Franck L, Dhawan A, Gibson F. The stories of young people living with a liver transplant. Qual Health Res. 2010; 20(8):1076-90.

5. De Sarasqueta P. Mortalidad neonatal y posneonatal en recién nacidos de peso menor a $2500 \mathrm{~g}$ en la República Argentina (1990-1997). Arch Argent Pediatr. 2001; 99(1):5861.

6. Silva N, Pereira M, Otto C, Ravens-Siebers U, et al. Do 8-to 18-year-old children/adolescents with chronic physical health conditions have worse health-related quality of life tan their healthy peers? A meta-analysis of studies using the KIDSCREEN questionnaires. Qual Life Res. 2019; 28(7):1725-50.

7. Grootenhuis MA, Koopman HM, Verrips EGH, Vogels AGC, et al. Health-related quality of life problems of children aged 8-11 years with a chronic disease. Dev Neurorehabil. 2007; 10(1):27-33.

8. Moreno-Jiménez B, Kern de Castro E. Calidad de vida relacionada con la salud infantil y el trasplante de órganos: una revisión de literatura. Rev Colomb Psicol. 2005; (14): 46-52.

9. Krmar R, Eymann A, Ramírez J, Ferraris J. Quality of life after kidney transplantation in children. Transplantation. 1997; 64(3):540-1.

10. McKeever P. Siblings of chronically ill children: A literature review with implications for research and practice. Am J Orthopsychiatry. 1983; 53(2):209-18.
11. KIDSCREEN Group Europe. The KIDSCREEN Questionnaires. Quality of Life Questionnaires for Children and Adolescents Handbook. Lengerich: Papst Science Publisher; 2006.

12. Sánchez C, Eymann A, De Cunto C. Calidad de vida relacionada con la salud en niños con afecciones crónicas alojadas en un alojamiento integral en la Ciudad de Buenos Aires. Arch Argent Pediatr. 2014; 112(3):231-8.

13. Currie CE, Elton RA, Tood J, Platt S. Indicators of socioeconomic status for adolescents: the WHO Health Behaviour in School-aged Children survey. Health Educ Res. 1997; 12(3):385-97.

14. UNESCO Institute for Statistics. International Standard Classification of Education (ISCED) 2011. Montreal: UNESCO; 2012.

15. Schaloch R, Verdugo Alonso M. Manual para profesionales dela educación, salud y servicios sociales. Madrid: Alianza; 2003.

16. Stewart DA, Stein A, Forrest GC, Clark DM. Psychological adjustment in siblings of children with chronic lifethreatening illness: a research note.JChild Psycol Psychiatry. 1992; 33(4):779-84

17. Fanos J, Fahrner K, Jelveh M, King R, et al. The siblings center: a pilot program for siblings of children and adolescents with a serious medical condition. J Pediatr. 2005; 146(6):831-5.

18. Tong A, Lowe A, Sainsbury P, Craig JC. Parental perspectives on caring for child with chronic kidney: an in-depth interview study. Child Care Health Dev. 2010; 36(4):549-57.

19. Vinaccia S, Orozco L. Aspectos psicosociales asociados con la calidad de vida de personas con enfermedades crónicas. Divers Perspect Psicol. 2005; 1(2):125-37.

20. Blum-Gordillo B, Gordillo Paniagua G, Grünberg J. Psiconefrología y econefrología. In GordilloPaniagua G(ed.). Nefrología Pediátrica. Madrid: Mosby; 1996.Págs.465-81.

21. O'Brien I, Duffy A, Nicholl H. Impact of childhood chronic illnesses on siblings: a literature review. Br J Nurs. 2009; 18(22):1358.60-5. 


\section{Annex \\ Description of KIDSCREEN-52 dimensions}

1 Physical well-being

2 Psychological well-being

3 Moods and emotions

4 Self-perception

5 Autonomy

6 Parent relations and home life

7 Social support and peers

8 School environment

9 Social acceptance

10 Financial resources
It explores the level of the child's physical activity, energy, and fitness.

It examines the psychological well-being of the child, including positive emotions and satisfaction with life.

It covers how much the child experiences depressive moods and emotions and stressful feelings.

It explores whether the appearance of the body is viewed positively or negatively by the child. Body image is explored by questions concerning satisfaction with looks as well as with clothes and other personal accessories.

It looks at the opportunity given to a child to create their social and leisure time.

It examines the relationship with the parents and the atmosphere at home.

It examines the nature of the child's relationships with other children.

It explores a child's perception of their cognitive capacity, learning, and concentration, and their feelings about school.

It covers the aspect of feeling rejected by peers.

It assesses the child's perceived quality of their financial resources.

These are examples of the questions included in the questionnaire:

Have you had enough money to do the same things as your friends?

Have you had enough money for your expenses? 